\title{
Clinicopathological features for predicting central and lateral lymph node metastasis in papillary thyroid microcarcinoma: Analysis of 66 cases that underwent central and lateral lymph node dissection
}

\author{
YANG TAO $^{1}$, CHONGJIE WANG $^{1}$, LIYE LI $^{1}$, HAIJUN XING ${ }^{1}$, YUN BAI $^{1}$, \\ BING HAN ${ }^{1}$, ZHIYAN LIU ${ }^{2}$, XIANGSHAN YANG ${ }^{3}$ and SHOURONG ZHU ${ }^{1}$ \\ ${ }^{1}$ Department of Head and Neck, Affiliated Hospital of Shandong Medical Sciences, Jinan, Shandong 250031; \\ ${ }^{2}$ Department of Pathology, Qilu Hospital, Jinan, Shandong 250012; ${ }^{3}$ Department of Pathology, \\ Affiliated Hospital of Shandong Medical Sciences, Jinan, Shandong 250031, P.R. China
}

Received June 29, 2016; Accepted November 8, 2016

DOI: $10.3892 / \mathrm{mco} .2016 .1085$

\begin{abstract}
Currently the surgical approach for papillary thyroid microcarcinoma (PTMC), particularly the range of lymph node dissection, remains controversial. The present study aims to evaluate the risk factors for central and lateral lymph node metastasis (CLNM and LLNM) for appropriate clinical decision of neck lymph node dissection in PTMC. A total of 66 cases of PTMC that underwent unilateral or bilateral lobectomy plus prophylactic cervical lymph node dissection were collected for clinicopathological evaluation, including age, gender, tumor size, subtypes, extrathyroidal invasion, multifocality, calcifications, loss of cellular polarity/cohesiveness (LOP/C) in the invasive front, CLNM and LLNM, and retrospectively analysis. Univariate analysis revealed that LOP/C was significantly associated with CLNM ( $\mathrm{P}=0.001)$ and LLNM $(\mathrm{P}<0.0001)$. The male gender was a risk factor of CLNM $(\mathrm{P}=0.04)$, while the age $<45$ years, tumor size $>0.5 \mathrm{~cm}$ and multifocality were high-risk factors of LLNM $(\mathrm{P}=0.022,0.044$ and 0.005 , respectively). Multivariable analysis revealed that $\mathrm{LOP} / \mathrm{C}$ was significantly associated with CLNM $[\mathrm{P}=0.007$, odds ratio $(\mathrm{OR})=7.765,95 \%$ confidence interval $(\mathrm{CI})=1.773-33.996]$ and LLNM $[\mathrm{P}=0.029, \mathrm{OR}=5.717$, $95 \% \mathrm{CI}=1.190-27.470]$. Both multivariable analysis and $\chi^{2}$ test revealed that CLNM was another important high-risk factor of $\operatorname{LLNM}\left(\mathrm{P}=0.021, \mathrm{OR}=5.444,95 \% \mathrm{CI}=1.290-22.969, \chi^{2}=17.867\right.$,
\end{abstract}

Correspondence to: Dr Chongjie Wang, Department of Head and Neck, Affiliated Hospital of Shandong Medical Sciences, 38 Wuyingshan Road, Tianqiao, Jinan, Shandong 250031, P.R. China E-mail: wcj198310@163.com

Key words: papillary thyroid microcarcinoma, central/lateral lymph node metastasis, prophylactic central lymph node dissection, prophylactic lateral lymph node dissection, loss of cellular polarity/cohesiveness
$\mathrm{P}<0.001)$. The present study revealed that prophylactic central lymph node dissection is essential for PTMC surgery and that prophylactic lateral lymph node dissection is recommend for patients with LOP/C and CLNM, which can be performed by intraoperative frozen section pathological examination. This must be considered discreetly in the case of patients with age $<45$ years, tumor size $>0.5 \mathrm{~cm}$ and multifocal lesions.

\section{Introduction}

The annual incidence of thyroid carcinoma is $6.2 \%$ (1) and accounts for $2.7 \%$ of all malignant tumor types in females worldwide $(2,3)$. Papillary thyroid microcarcinoma (PTMC), which is defined as a papillary carcinoma with the dimensions equal to or $<1.0 \mathrm{~cm}$, according to the World Health Organization classification (4), accounts for 6-35\% of thyroid carcinoma and 35.7-61.5\% of papillary thyroid carcinoma (PTC) (5-10). PTMC is considered with favorable biological features and good long-term prognosis, as the 10-year disease-specific survival of $99.5 \%$ (11). The rate of neck lymph metastasis is $3.1-45.7 \%$, and the sites include level II, III, IV, V, VI (12-14). Lymph node metastasis, particularly central lymph node metastasis (CLNM), is considered to be the most important risk factor associated with recurrence (15-17).

Currently, the surgical approach for PTMC, particularly the ranges of lymph nodes dissection remains controversial $(18,19)$. Although numerous previous studies have suggested that unilateral or bilateral lobectomy, plus prophylactic central lymph node dissection (PCLND; dissection of the level VI lymph nodes which lie in central position of the neck $(6,20)$, including prelaryngeal, pretracheal and paratracheal lymph nodes) for PTMC is enough (21-23), and even overtreatment is performed when no positive lymph nodes were identified in clinical examination (cN0), others still insist that prophylactic lateral lymph node dissection (PLLND) should be performed in certain conditions $(24,25)$. PCLND may cause temporary parathyroid laryngeal damage and injury to laryngeal 
nerves (26); PLLND may damage accessory nerves, cervical plexus and cause additional complications. Neck ultrasound (US) and contrast-enhanced computed tomography (CT) are widely used for preoperative imaging to visualize the lymph metastasis; unfortunately, both US and contrast-enhanced CT are not particularly accurate, with low sensitivities of 23-53.2 and $41-66.7 \%$, respectively $(27,28)$. Therefore, the risk factors of CLNM and LLNM are important for surgeons to determine the range of neck lymph dissection. Current research demonstrated that age $\geq 45$ years, tumor size $>0.5 \mathrm{~cm}$, extrathyroid invasion, multifocality and calcifications were all possible risk factors of CLNM (13,16-20); however, few previous studies have investigated predicting factors of LLNM.

Loss of cellular polarity/cohesiveness (LOP/C) in the invasive front was considered to be a useful morphological feature of the epithelial-mesenchymal transition (EMT) under hematoxylin and eosin staining (29). LOP refers to a phenomenon in which the carcinoma cells are arranged in micropapillary structures with a fibrous axis or irregular tubular patterns, and the nuclei were round and located in the apical cytoplasm, or flat and located centrally (30-32). LOC means that the carcinoma cells were loosely arranged, singly or in small clusters resembling foamy histiocytes or in micropapillary structures (29-32). The invasive front was defined as the interface between the tumor and the adjacent non-neoplastic tissue when the tumor exhibited invasive growth, in which desmoplasia is usually observed (29-32). When LOP/C was definitely present in at least two sites in the invasive front, it is considered to be significant (30). In PTC, LOP/C is associated with increased risk of lymph node metastasis, extrathyroid invasion and aggressive clinical behavior (29); however, the role of LOP/C in PTMC remains to be investigated. In the present study, LOP/C in PTMC was observed and analyzed.

\section{Materials and methods}

Patients. The clinical data of 66 patients with PTMC, who underwent unilateral or bilateral lobectomy plus prophylactic cervical lymph node dissections between January 2008 and June 2015 in the Affiliated Hospital of Shandong Medical Sciences (Shandong, China) were retrospectively analyzed. All cases were unilateral lesion and cervical lymph node cNO. The age range was 19-69 years (median, 43.5 years) and the ratio of male:female was 1:4.08. All PTMC patients were confirmed by intraoperative frozen section pathological examination, followed by unilateral or bilateral lobectomy and prophylactic ipsilateral regional lymphadenectomy, including level II, III, IV, V, VI, were performed. Postoperative paraffin section histopathology examinations were performed and pathological features, including subtypes, tumor size, extrathyroidal invasion, multifocality, calcifications, LOP/C, CLNM and LLNM were subjected to a meticulous histopathology examination by two pathologists (Zhiyan Liu and Xiangshan Yang).

Statistical analysis. Fisher's exact test or $\chi^{2}$ test, and binary logistic regression were used to investigate the cases using SPSS software (version 17.0; SPSS, Inc., Chicago, IL, USA). $\mathrm{P}<0.05$ was considered to indicate a statistically significant difference.
Table I. Neck lymph metastasis of 66 papillary thyroid microcarcinoma cases.

\begin{tabular}{lcc}
\hline & \multicolumn{2}{c}{ Neck lymph node metastasis } \\
\cline { 2 - 3 } $\begin{array}{l}\text { Neck lymph } \\
\text { node stage }\end{array}$ & $\begin{array}{c}\text { Positive, } \\
\mathrm{n}(\%)\end{array}$ & $\begin{array}{c}\text { Negative, } \\
\mathrm{n}(\%)\end{array}$ \\
\hline II & $11(20.0)$ & $55(80.0)$ \\
III & $20(30.3)$ & $46(69.7)$ \\
IV & $17(25.8)$ & $49(74.2)$ \\
V & $3(4.8)$ & $63(95.2)$ \\
VI & $37(56.1)$ & $29(43.9)$ \\
\hline
\end{tabular}

\section{Results}

Neck lymph metastasis of 66 PTMC cases. A total of $60.6 \%$ (44/66) of cases exhibited neck lymph metastasis, including central and lateral. Only 36.4\% (24/66) cases exhibited CLNM and LLNM simultaneously, $13.6 \%(10 / 66)$ have CLNM without LLNM and 9.1\% (6/66) have LLNM only. The lymph node metastasis rate of level II, III, IV demonstrated no statistical significance $\left(20,30.3\right.$ and 25.8 , respectively, $\chi^{2}=3.465$, $\mathrm{P}=0.177)$. Compared with these groups, level VI was higher with a rate of $56.1 \%\left(37 / 66, \chi^{2}=25.871, \mathrm{P}<0.0001\right)$ and level V was lower $\left(4.8 \%, 3 / 66, \chi^{2}=16.404, \mathrm{P}<0.01\right)$ (Table I).

Univariate analysis outcome of the high-risk factors of total neck lymph metastasis of PTMC. Univariate analysis revealed that LOP/C was significantly associated with both central or lateral lymph metastasis $(\mathrm{P}=0.001$ and $\mathrm{P}<0.0001)$, and the male gender exhibited a statistical significant difference compared with female in CLNM (76.9 vs. $45.3 \%, \mathrm{P}=0.04$ ), while the age $<45$ years, tumor size $>0.5 \mathrm{~cm}$ and multifocality were high-risk factors of LLNM ( $\mathrm{P}=0.022,0.044$ and 0.005 , respectively). Extrathyroid invasion and calcifications were demonstrated to be not statistically significant with CLNM and LLNM (Table II).

The data of binary logistic regression for outcome of the central and lateral lymph metastasis risk factors of PTMC revealed that $\mathrm{LOP} / \mathrm{C}$ was significantly associated with CLNM $(\mathrm{P}=0.007)$ and LLNM $(\mathrm{P}=0.029)$ (Tables III and IV). Both multivariable analysis and $\chi^{2}$ test revealed that CLNM was another important risk factor of LLNM ( $\mathrm{P}=0.021$; Table IV) $\left(\chi^{2}=17.867, \mathrm{P}<0.001\right.$, Table V). Gender, age, subtypes, extrathyroid invasion, multifocality and calcifications faile to reach statistical significance for either CLNM or LLNM (Tables III and IV).

\section{Discussion}

The male gender and an age $\geq 45$ have been consistently recognized as independent risk factors of lymph metastasis in thyroid carcinoma (33). However, in PTMC, this view is remains controversial. The result of Zhao et al (34) shows male gender and age $\geq 45$ are at a higher risk of lymph node metastasis; however, certain other previous studies demonstrated that no statistically significant association existed between 
Table II. Univariate analysis of papillary thyroid microcarcinoma total neck lymph metastasis.

\begin{tabular}{|c|c|c|c|c|c|}
\hline Risk factor & Cases, n & $\begin{array}{l}\text { Central lymph node } \\
\text { metastasis, n }(\%)\end{array}$ & P-value & $\begin{array}{l}\text { Lateral lymph node } \\
\text { metastasis, n (\%) }\end{array}$ & P-value \\
\hline \multicolumn{6}{|l|}{ Gender } \\
\hline Male & 13 & $10(76.9)$ & \multirow[t]{2}{*}{$0.040^{\mathrm{a}}$} & $8(61.5)$ & \multirow[t]{2}{*}{0.086} \\
\hline Female & 53 & $24(45.3)$ & & $19(35.8)$ & \\
\hline \multicolumn{6}{|l|}{ Age, years } \\
\hline$\geq 45$ & 33 & $14(47.4)$ & \multirow[t]{2}{*}{0.109} & $9(27.3)$ & \multirow[t]{2}{*}{$0.022^{\mathrm{a}}$} \\
\hline$<45$ & 33 & $20(60.6)$ & & $18(54.5)$ & \\
\hline \multicolumn{6}{|l|}{ Tumor size } \\
\hline$\leq 0.5 \mathrm{~cm}$ & 34 & $15(44.1)$ & \multirow[t]{2}{*}{0.160} & $10(29.4)$ & \multirow[t]{2}{*}{$0.044^{\mathrm{a}}$} \\
\hline$>0.5 \mathrm{~cm}$ & 32 & $19(59.4)$ & & $17(53.1)$ & \\
\hline \multicolumn{6}{|l|}{ Subtypes } \\
\hline CPV & 31 & $18(58.1)$ & \multirow[t]{5}{*}{0.788} & $15(48.4)$ & \multirow[t]{5}{*}{0.643} \\
\hline UCPV & 17 & $8(47.1)$ & & $7(41.2)$ & \\
\hline FCV & 10 & $4(40.0)$ & & $2(20.0)$ & \\
\hline TCV & 5 & $3(60.0)$ & & $2(40.0)$ & \\
\hline DSV & 3 & $1(33.3)$ & & $1(33.3)$ & \\
\hline \multicolumn{6}{|c|}{ Extrathyroid invasion } \\
\hline Yes & 27 & $13(48.1)$ & \multirow[t]{2}{*}{0.419} & $10(37.0)$ & \multirow[t]{2}{*}{0.392} \\
\hline No & 39 & $21(53.8)$ & & $17(43.9)$ & \\
\hline \multicolumn{6}{|c|}{ Multifocality } \\
\hline Yes & 38 & $22(57.9)$ & \multirow[t]{2}{*}{0.169} & $21(55.3)$ & \multirow[t]{2}{*}{$0.005^{\mathrm{a}}$} \\
\hline No & 28 & $12(42.9)$ & & $6(21.4)$ & \\
\hline \multicolumn{6}{|c|}{ Calcifications } \\
\hline Yes & 10 & $6(66.7)$ & \multirow[t]{2}{*}{0.269} & $6(66.7)$ & \multirow[t]{2}{*}{0.093} \\
\hline No & 56 & $28(49.1)$ & & $21(36.8)$ & \\
\hline \multicolumn{6}{|l|}{$\mathrm{LOP} / \mathrm{C}$} \\
\hline Yes & 23 & $18(78.3)$ & \multirow[t]{2}{*}{$0.001^{\mathrm{a}}$} & $17(73.9)^{\mathrm{b}}$ & \multirow[t]{2}{*}{$0.0001^{\mathrm{a}}$} \\
\hline No & 43 & $16(37.2)$ & & $10(23.3)$ & \\
\hline
\end{tabular}

${ }^{\mathrm{a}} \mathrm{P}<0.05$; ${ }^{\mathrm{b}}$ The rate of LLNM was 83.3\% (15/18) when LOP/C and CLNM existed simultaneously. CPV, classical papillary variant; UCPV, unclassical papillary variant; FCV, follicular variant; TCV, tall cell variant; DSV, diffuse sclerosing variant; LOP/C, loss of cellular polarity/cohesiveness; LLNM, lateral lymph node metastasis; CLNM, central lymph node metastasis.

them $(20,34,35)$. The research of 1,990 PTMC cases reported that the male incidence of thyroid carcinoma was associated with absence of environment protection mechanisms and emphasized that surgical intervention may possibly improve male's prognosis (36). An age $\geq 45$ is commonly considered as a risk factor for tumor recurrence and lymph node metastasis, however, other literature has suggested that adolescents tend to develop neck lymph node metastasis (35-37). The univariate analysis revealed that male gender tended to associate more with CLNM $(10 / 13,76.9 \%, \mathrm{P}=0.04)$ and patients $<45$ years were more at risk of LLNM $(18 / 33,54.5 \%, P=0.022)$. However, in the multivariate analysis, these factors failed to reach statistical significance (Tables III and IV).

Tumor size $>0.5 \mathrm{~cm}$ is also recognized as a risk factor for lymph node metastasis in PTMC $(17,35)$. PTMC with size $>0.5 \mathrm{~cm}$ may be associated with more vascular and extrathyroid invasion, more incidence in females and more CLNM (38). Lee et al (39) demonstrated that PTMC CLNM of tumor size $\leq 0.5 \mathrm{~cm}$ compared with size $>0.5 \mathrm{~cm}$ was 18.2 vs. $29.2 \%(\mathrm{P}=0.018)$, and LLNM was only $5.5 \%$ (39). The present univariate analysis results revealed more LLNM of PTMC $>0.5 \mathrm{~cm}$ (53.1 vs. $29.4 \%, \mathrm{P}=0.044)$; however, it still failed to reach statistical significance in the multivariate analysis.

A total of 5 subtypes were found in the 66 cases, according to pathological features (40): Classical papillary variant (CPV), unclassical papillary variant (UCPV), follicular variant (FCV), tall cell variant (TCV) and diffuse sclerosing variant (DSV). TCV and DSV were considered as aggressive variants (41) and tend to exhibit more aggressive pathological characteristics, including higher rates of extrathyroidal extension compared with classic PTMC, more multifocality in TCV and more lymph metastasis in DSV; however, the survival appears to be similar (42). In the present study, CLNM and LLNM exhibited no statistically significant difference between each subtype, and subtype was not a high risk factor of CLNM and LLNM $(\mathrm{P}=0.251$ and 0.381 , respectively; Tables III and IV). However, 
Table III. Multivariable analysis of risk factors for papillary thyroid microcarcinoma central lymph node metastasis.

\begin{tabular}{|c|c|c|c|c|c|c|}
\hline Risk factor & $\begin{array}{l}\text { Partial regression } \\
\text { coefficient B }\end{array}$ & SE & Wald & DOF & P-value & OR \\
\hline Age & 0.330 & 0.050 & 0.425 & 1 & 0.515 & 1.033 \\
\hline Gender & 1.698 & 0.941 & 3.256 & 1 & 0.071 & 5.461 \\
\hline Tumor size & -0.306 & 1.058 & 0.084 & 1 & 0.772 & 0.736 \\
\hline Subtype & 0.227 & 0.260 & 0.768 & 1 & 0.381 & 1.225 \\
\hline Extrathyroid invasion & -0.224 & 0.669 & 0.133 & 1 & 0.716 & 0.784 \\
\hline Multifocality & -0.950 & 0.828 & 1.315 & 1 & 0.251 & 0.387 \\
\hline Calcifications & 1.671 & 1.095 & 2.329 & 1 & 0.127 & 5.316 \\
\hline $\mathrm{LOP} / \mathrm{C}$ & 2.050 & 0.753 & 7.401 & 1 & $0.007^{\mathrm{a}}$ & 7.765 \\
\hline
\end{tabular}

${ }^{\mathrm{a}} \mathrm{P}<0.01$; OR=7.765; 95\% confidence interval=1.773-33.996. LOP/C, loss of cellular polarity/cohesiveness; SE, standard error; DOF, degrees of freedom; OR, odds ratio.

Table IV. Multivariable analysis of risk factors for papillary thyroid microcarcinoma lateral lymph node metastasis.

\begin{tabular}{|c|c|c|c|c|c|c|}
\hline Risk factor & $\begin{array}{l}\text { Partial regression } \\
\text { coefficient B }\end{array}$ & SE & Wald & DOF & P-value & OR \\
\hline Age & 0.007 & 0.060 & 0.014 & 1 & 0.906 & 1.007 \\
\hline Gender & 0.353 & 1.062 & 0.111 & 1 & 0.739 & 1.424 \\
\hline Tumor size & -0.773 & 1.373 & 0.317 & 1 & 0.573 & 0.462 \\
\hline Subtype & 0.270 & 0.336 & 0.647 & 1 & 0.421 & 1.311 \\
\hline Extrathyroid invasion & -1.017 & 0.847 & 1.440 & 1 & 0.230 & 0.362 \\
\hline Multifocality & -0.910 & 1.020 & 0.796 & 1 & 0.372 & 2.485 \\
\hline Calcifications & 1.020 & 1.166 & 0.766 & 1 & 0.382 & 2.774 \\
\hline $\mathrm{LOP} / \mathrm{C}$ & 1.743 & 0.801 & 4.739 & 1 & $0.029^{\mathrm{a}}$ & 5.717 \\
\hline CLNM & 1.694 & 0.735 & 5.321 & 1 & $0.021^{\mathrm{b}}$ & 5.444 \\
\hline
\end{tabular}

${ }^{\mathrm{a}} \mathrm{P}<0.05, \mathrm{OR}=5.717,95 \%$ confidence interval $=1.190-27.470 ;{ }^{\mathrm{b}} \mathrm{P}<0.05$, odds ratio=5.444, 95\% CI (1.290 22.969). LOP/C, loss of cellular polarity/cohesiveness; SE, standard error; DOF, degrees of freedom; CLNM, central lymph node metastasis; OR, odds ratio.

Table V. Association between central lymph node metastasis and lateral lymph node metastasis.

\begin{tabular}{lcccr}
\hline & & \multicolumn{2}{c}{$\begin{array}{c}\text { Lateral lymph node } \\
\text { metastasis, } \mathrm{n}(\%)\end{array}$} \\
\cline { 3 - 5 } Central lymph node metastasis & $\mathrm{n}$ & Positive & Negative & $\chi^{2}$ \\
\hline Positive & 34 & $24(70.6)$ & $10(29.4)$ & $17.867^{\text {a }}$ \\
Negative & 32 & $6(18.8)$ & $23(81.2)$ & \\
\hline
\end{tabular}

${ }^{\mathrm{a}} \mathrm{P}<0.001$

due to a reduced number of DSV and TSV, further research is required.

Extrathyroid invasion, multifocality and calcification are all valuable high-risk factors of lymph metastasis of PTMC (43-45). PTMC with these pathological characters exhibit more aggressive biological behavior (42). Multifocality was considered the intraglandular spread of the primary tumor, which indicated the tumor cells were apt to shed off from primary lesion and distribute in thyroid $(46,47)$. When the primary lesion penetrated the fibrous capsule of thyroid, the tumor cells metastasized easier without the restrain of the capsule (29). Shindo et al (44) and Chow et al (48) reported that neck lymph node metastasis was significantly correlated with tumor multifocality. Multiple microcalcifications were recognized as an important feature of malignancy, and PTMC with calcification was detected with a large size and higher 
lymph node ratio compared with non-calcified lesions (45). Unfortunately, these options remain controversial $(34,38)$. The present univariate analysis result revealed that multifocality was a significant high-risk factor for LLNM, however, in the multivariate analysis, they were not significant.

The EMT is a crucial step in the process of migration of carcinoma tumors from the primary site into surrounding tissues (49-51), which features a loss of epithelial properties and the acquisition of mesenchymal properties, including the loss of apical-basal polarity, loss of cell-cell adhesion, loss of E-cadherin expression, and overexpression of vimentin, epidermal growth factor receptor (EGFR), matrix metalloproteinase-9, TGF- $\beta$, NFkb and integrin pathway members in the invasive front $(52,53)$. However, the affirmation of the EMT requires examination of biomarkers, including E-cadherin, $\mathrm{N}$-cadherin, vimentin and fibronectin $(53,54)$. LOP/C in the invasive front is considered to be a be a useful morphological feature of the EMT, and can be observed directly under hematoxylin and eosin staining, without immunohistochemical examination (29). PTCs with LOP/C was significantly correlated with poor clinical outcome as extrathyroid invasion and lymph node metastasis more frequently, and the majority exhibited extrathyroid invasion and were in an advanced tumor stage at surgery (29-32). The present research revealed that in PTMC, more multifocality $\left(20 / 23\right.$ vs. $18 / 43, \chi^{2}=12.476$, $\mathrm{P}<0.0001), \mathrm{CLNM}$ and LLNM were more observed in the cases with LOP/C compared with the cases without (Table II), which proved that the invasive capacity of tumor was enhanced, and LOP/C was confirmed to be a high-risk factor of CLNM and LLNM ( $\mathrm{P}=0.007$ and 0.029, respectively; Tables III and IV).

PCLND is recommended as the standard treatment of PTMC; however, the controversy has never ceased. Certain surgeons advocate that PCLND must not be recommended to patients with PTMC, for its reduced malignancy, and PCLND may cause perioperative side effect, including hypoparathyroidism and laryngeal nerve injury $(55,56)$. Additionally, CLNM does not affect the PTMC prognosis (57), even with re-operation following recurrence (58). By contrast, other clinicians suggest that PCLND can reduce the recurrence and improve the survival $(59,60)$. Previous research has revealed that CLNM of PTMC, without risk factors such as male gender, age $\geq 45$, extrathyroid invasion, multifocality and aggressive subtype, was only 6.80-8.13\% and PCLND was not recommend $(20,36)$. On the contrary, PCLND was necessary in PTMC with these factors $(13,25)$. However, in the present study, the high risk factors of CLNM were male gender and LOP/C (Tables III and IV). A total of 56.1\% (37/66) of patients exhibited CLNM, while the rate of CLNM with male gender and LOP/C was $87.0 \%$ (20/23) compared with $32.5 \%(14 / 43)$ in patients without these factors $\left(\chi^{2}=10.267, \mathrm{P}<0.001\right)$. These data indicate that PCLND may be necessary for PTMC, regardless of the high risk factors.

PLLND of PTMC has not been emphasized due to of the low incidence of LLNM; for example, 5.5\% (39) and less effect on the survival (23). However, Zeng et al (25) found that the rate of LLNM was $30.5 \%$ (43/141) and the number of positive central lymph node $\geq 2$, accompanying with Hashimoto's thyroiditis and extrathyroidal extension were the independent predictive factors for LLNM (25). Another analysis revealed that the presence of CLNM, upper third location of malig- nancy and tumor size were independent factors for predicting LLNM (61). The present result demonstrated that $45.5 \%$ (30/66) cases exhibited LLNM and the ratio of II, III, IV, V was $20,30.3,25.8$ and $4.8 \%$, respectively. A total of $70.6 \%(24 / 34)$ of the cases with CLNM had LLNM and it was significantly higher compared with the $18.8 \%(6 / 32)$ of the cases without CLNM $\left(\chi^{2}=17.867, \mathrm{P}<0.001\right.$; Table V), and the ratio was $81.8 \%$ $(18 / 22)$ when the number of CLNM $\geq 2$. CLNM and LOP/C were high-risk factors of LLNM in both univariate and multivariate analyses; The rate of LLNM was $83.3 \%$ (15/18) when LOP/C and CLNM existed simultaneously. An age $<45$ years, tumor size $>0.5 \mathrm{~cm}$ and multifocality were significant in the univariate analysis. The rate of LLND in PTMC without age $<45$ years, tumor size $>0.5 \mathrm{~cm}$, multifocality, LOP/C and CLNM was $0 \%(0 / 9)$. In the factors mentioned above, CLNM and $\mathrm{LOP} / \mathrm{C}$ were important and useful since intraoperative frozen section pathological examination can confirm them and assist the surgeon to make the decision whether PLLND should be performed, even though no evidence suggests that a level IV node is the sentinel of II, III, IV or V in anatomy, and the mechanism remains unclear.

According to the present results, CLNM tends to occur in patients with male gender and LOP/C, while LLNM is more likely to be associated with age $<45$ years, tumor size $>0.5 \mathrm{~cm}$, multifocality, LOP/C and CLNM. PTMC is not an occult cancer and it can act like larger PTC (62). Currently, no effective preoperative examination exists to confirm the existence of LLNM, when clinical examination of cervical lymph node is negative. The present results revealed that $45.5 \%(30 / 66)$ of cases had LLNM and the ratio of II, III, IV and V was 20,30.3, 25.8 and $4.8 \%$, respectively; therefore, it may not be enough for certain PTMC patients if only CLNM is performed. Therefore, intraoperative frozen section pathological examination of high-risk factors will be useful to direct the surgical approach of PTMC and reduce the regional recurrence. PLLND is recommend intensely if LOP/C and CLNM are performed by intraoperative frozen section pathological examination and must be considered in patients with the age $<45$ years, tumor size $>0.5 \mathrm{~cm}$ and multifocal lesions.

\section{Acknowledgements}

The authors would like to thank Professor Zhiyan Liu (Department of Pathology, Qilu Hospital, Shandong, China) for suggesting the direction of pathological examination for us. The present study was supported by the subject of Shandong Province Science and Technology Office, 'Research of relationship between pathological subtypes of papillary thyroid microcarcinoma and cervical lymph node metastasis' (no. 2013YD18034).

\section{References}

1. Jemal A, Siegel R, Ward E, Hao Y, Xu J and Thun MJ: Cancer statistics, 2009. CA Cancer J Clin 59: 225-249, 2009.

2. Lundgren CI, Hall P, Dickman PW and Zedenius J: Clinically significant prognostic factors for differentiated thyroid carcinoma: A population-based, nested case-control study. Cancer 106: 524-531, 2006.

3. Ferlay J, Shin HR, Bray F, Forman D, Mathers C and Parkin DM: Estimates of worldwide burden of cancer in 2008: GLOBOCAN 2008. Int J Cancer 127: 2893-2917, 2010. 
4. Sobin LH: Histological typing of thyroid tumours. Histopathology 16: 513, 1990.

5. Lee J, Song Y and Soh EY: Central lymph node metastasis is an important prognostic factor in patients with papillary thyroid microcarcinoma. J Korean Med Sci 29: 48-52, 2014.

6. American Thyroid Association (ATA) Guidelines Taskforce on Thyroid Nodules and Differentiated Thyroid Cancer; Cooper DS, Doherty GM, Haugen BR, Kloos RT, Lee SL, Mandel SJ, Mazzaferri EL, McIver B, Pacini F, et al: Revised American Thyroid Association management guidelines for patients with thyroid nodules and differentiated thyroid cancer. Thyroid 19: 1167-1214, 2009 .

7. Pfister DG, Spencer S, Brizel DM, Burtness B, Busse PM, Caudell JJ, Cmelak AJ, Colevas AD, Dunphy F, Eisele DW, et al: Head and neck cancers, Version 2.2014. Clinical practice guidelines in oncology. J Natl Compr Canc Netw 12: 1454-1487, 2014.

8. Yoshida A: Guidelines for the management of thyroid tumors. Nihon Geka Gakkai Zasshi 113: 507-601, 2012 (In Japanese).

9. Teng W, Liu YF, Gao M and Huang G: Management guidelines for patients with thyroid nodules and differentiated thyroid cancer. Chin J Clin Oncol 17: 1249-1272, 2012.

10. Chen Q, Zou XH, Wei T, Huang QS, Sun YH and Zhu JQ: Prediction of ipsilateral and contralateral central lymph node metastasis in unilateral papillary thyroid carcinoma: A retrospective study. Gland Surg 4: 288-294, 2015.

11. Kuo EJ, Goffredo P, Sosa JA and Roman SA: Aggressive variants of papillary thyroid microcarcinoma are associated with extrathyroidal spread and lymph-node metastases: A population-level analysis. Thyroid 23: 1305-1311, 2013

12. Kebebew E: Heraditary non-medullary thyroid cancer. World J Surg 32: 678-682, 2008

13. Yang Y, Chen C, Chen Z, Jiang J, Chen Y, Jin L, Guo G, Zhang X and Ye T: Prediction of central compartment lymph node metastasis in papillary thyroid microcarcinoma. Clin Endocrinol (Oxf) 81: 282-288, 2014.

14. Nam-Goong IS, Kim HY, Gong G, Lee HK, Hong SJ, Kim WB and Shong YK: Ultrasonography-guided fine-needle aspiration of thyroid incidentaloma: Correlation with pathological findings. Clin Endocrinol (Oxf) 60: 21-28, 2004

15. Hay ID, Hutchinson ME, Gonzalez-Losada T, McIver B, Reinalda ME, Grant CS, Thompson GB, Sebo TJ and Goellner JR: Papillary thyroid microcarcinoma: A study of 900 cases observed in a 60-year period. Surgery 144: 980-988, 2008

16. Pisanu A, Reccia I, Nardello O and Uccheddu A: Risk factors for nodal metastasis and recurrence among patients with papillary thyroid microcarcinoma: Differences in clinical relevance between nonincidental and incidental tumors. World J Surg 33 460-468, 2009.

17. Usluogullari CA, Onal ED, Ozdemir E, Ucler R, Kiyak G, Ersoy PE, Yalcin S, Güler G, Ersoy R and Cakir B: A retrospective analysis of prognostic factors predictive of lymph-node metastasis and recurrence in thyroid papillary microcarcinoma. Minerva Endocrinol 40: 15-22, 2015.

18. Giordano D, Gradoni P, Oretti G, Molina E and Ferri T: Treatment and prognostic factors of papillary thyroid microcarcinoma. Clin Otolaryngol 35: 118-124, 2010

19. Garrel R, Tripodi C, Cartier C, Makeieff M, Crampette L and Guerrier B: Cervical lymphadenopathies signaling thyroid microcarcinoma. Case study and review of the literature. Eur Ann Otorhinolaryngol Head Neck Dis 128: 115-119, 2011.

20. Liu Z, Wang L, Yi P, Wang CY and Huang T: Risk factors for central lymph node metastasis of patients with papillary thyroid microcarcinoma: A meta-analysis. Int J Clin Exp Pathol 7: 932-937, 2014

21. De Pasquale L, Bastagli A, Moro GP and Ghilardi G: Thyroid microcarcinoma approach: A ten year experience. Ann Ital Chir 84: 533-539, 2013.

22. Pedrazzini L, Baroli A, Marzoli L, Guglielmi R and Papini E: Cancer recurrence in papillary thyroid microcarcinoma: A multivariate analysis on 231 patients with a 12-year follow-up. Minerva Endocrinol 38: 269-279, 2013.

23. Karatzas T, Vasileiadis I, Kapetanakis S, Karakostas E Chrousos G and Kouraklis G: Risk factors contributing to the difference in prognosis for papillary versus micropapillary thyroid carcinoma. Am J Surg 206: 586-593, 2013.

24. Shin HJ, Kim EK, Moon HJ, Yoon JH, Han KH and Kwak JY: Can increased tumoral vascularity be a quantitative predicting factor of lymph node metastasis in papillary thyroid microcarcinoma? Endocrine 47: 273-282, 2014.
25. Zeng RC, Zhang W, Gao EL, Cheng P, Huang GL, Zhang XH and $\mathrm{Li}$ Q: Number of central lymph node metastasis for predicting lateral lymph node metastasis in papillary thyroid microcarcinoma. Head Neck 36: 101-106, 2014.

26. Khairy GA and Al-Saif A: Incidental parathyroidectomy during thyroid resection: Incidence, risk factors, and outcome. Ann Saudi Med 31: 274-278, 2011.

27. Choi JS, Kim J, Kwak JY, Kim MJ, Chang HS and Kim EK Preoperative staging of papillary thyroid carcinoma: Comparison of ultrasound imaging and CT. AJR Am J Roentgenol 193: 871-878, 2009.

28. Hwang HS and Orloff LA: Efficacy of preoperative neck ultrasound in the detection of cervical lymph node metastasis from thyroid cancer. Laryngoscope 121: 487-491, 2011.

29. Liu Z, Kakudo K, Bai Y, Li Y, Ozaki T, Miyauchi A, Taniguchi E and Mori I: Loss of cellular polarity/cohesiveness in the invasive front of papillary thyroid carcinoma, a novel predictor for lymph node metastasis; possible morphological indicator of epithelial mesenchymal transition. J Clin Pathol 64: 325-329, 2011.

30. Bai Y, Kakudo K, Li Y, Liu Z, Ozaki T, Ito Y, Kihara M and Miyauchi A: Subclassification of non-solid-type papillary thyroid carcinoma identification of high-risk group in common type. Cancer Sci 99: 1908-1915, 2008.

31. Kakudo K, Tang W, Ito Y, Mori I, Nakamura Y and Miyauchi A Papillary carcinoma of the thyroid in Japan: Subclassification of common type and identification of low risk group. J Clin Pathol 57: 1041-1046, 2004

32. Tang W, Nakamura Y, Zuo H, Yasuoka H, Yang Q, Wang X, Nakamura M, Mori I, Miyauchi A and Kakudo K: Differentiation, proliferation and retinoid receptor status of papillary carcinoma of the thyroid. Pathol Int 53: 204-213, 2003.

33. Koo BS, Choi EC, Yoon YH, Kim DH, Kim EH and Lim YC: Predictive factors for ipsilateral or contralateral central lymph node metastasis in unilateral papillary thyroid carcinoma. Ann Surg 249: 840-844, 2009.

34. Zhao Q, Ming J, Liu C, Shi L, Xu X, Nie X and Huang T: Multifocality and total tumor diameter predict central neck lymph node metastases in papillary thyroid microcarcinoma. Ann Surg Oncol 20: 746-752, 2013.

35. Ghossein R, Ganly I, Biagini A, Robenshtok E, Rivera M and Tuttle RM: Prognostic factors in papillary microcarcinoma with emphasis on histologic subtyping: A clinicopathologic study of 148 cases. Thyroid 24: 245-253, 2014

36. Lu ZZ, Zhang Y, Wei SF, Li DS, Zhu QH, Sun SJ, Li M and Li LI: Outcome of papillary thyroid microcarcinoma: Study of 1,990 cases. Mol Clin Oncol 3: 672-676, 2015.

37. Handkiewicz-Junak D, Włoch J, Czarniecka A, Roskosz J, Prokurat A, Pomorski L, Krajewska J, Kropińska A, Kukulska A and Jarzab B: Completion total thyroidectomy in children with differentiated thyroid cancer. Endokrynol Pol 57: 356-361, 2006 (In Polish).

38. Kim E, Choi JY, Koo do H, Lee KE and Youn YK: Differences in the characteristics of papillary thyroid microcarcinoma $\leq 5 \mathrm{~mm}$ and $>5 \mathrm{~mm}$ in diameter. Head Neck 37: 694-697, 2015.

39. Lee HS, Park HS, Kim SW, Choi G, Park HS, Hong JC, Lee SG, Baek SM and Lee KD: Clinical characteristics of papillary thyroid microcarcinoma less than or equal to $5 \mathrm{~mm}$ on ultrasonography. Eur Arch Otorhinolaryngol 270: 2969-2974, 2013.

40. DeLellis RA, Lloyd RV, Heitz PU, Eng C (eds): World Health Organization Classification of Tumours. Pathology and Genetics of Tumours of Endocrine Organs. IARC Press, Lyon, pp57-103, 2004.

41. Silver CE, Owen RP, Rodrigo JP, Rinaldo A, Devaney KO and Ferlito A: Aggressive variants of papillary thyroid carcinoma. Head Neck 33: 1052-1059, 2011.

42. Kuo EJ, Goffredo P, Sosa JA and Roman SA: Aggressive variants of papillary thyroid microcarcinoma are associated with extrathyroidal spread and lymph-node metastases: A population-level analysis. Thyroid 23: 1305-1311, 2013.

43. Chung YS, Kim JY, Bae JS, Song BJ, Kim JS, Jeon HM, Jeong SS, Kim EK and Park WC: Lateral lymph node metastasis in papillary thyroid carcinoma: Results of therapeutic lymph node dissection. Thyroid 19: 241-246, 2009.

44. Shindo M, Wu JC, Park EE and Tanzella F: The importance of central compartment elective lymph node excision in the staging and treatment of papillary thyroid cancer. Arch Otolaryngol Head Neck Surg 132: 650-654, 2006.

45. Oh EM, Chung YS, Song WJ and Lee YD: The pattern and significance of the calcifications of papillary thyroid microcarcinoma presented in preoperative neck ultrasonography. Ann Surg Treat Res 86: 115-121, 2014. 
46. Mazeh H, Samet Y, Hochstein D, Mizrahi I, Ariel I, Eid A and Freund HR: Multifocality in well-differentiated thyroid carcinomas calls for total thyroidectomy. Am J Surg 201: 770-775, 2011

47. Sun W, Lan X, Zhang H, Dong W, Wang Z, He L, Zhang T and Liu S: Risk factors for central lymph node metastasis in CN0 papillary thyroid carcinoma: A Systematic Review and Meta-Analysis. PLoS One 10: e0139021, 2015.

48. Chow SM,Law SC, Chan JK, Au SK, Yau S and Lau WH: Papillary microcarcinoma of the thyroid-prognostic significance of lymph node metastasis and multifocality. Cancer 98: 31-40, 2003.

49. Christofori G: New signals from the invasive front. Nature 441 444-450, 2006

50. Sánchez-Tilló E, Liu Y, de Barrios O, Siles L, Fanlo L, Cuatrecasas M, Darling DS, Dean DC, Castells A and Postigo A EMT-activating transcription factors in cancer: Beyond EMT and tumor invasiveness. Cell Mol Life Sci 69: 3429-3456, 2012.

51. Cheng Y and $\mathrm{Cu}$ QC: Research advances in epithelial-mesenchymal transition in thyroid carcinoma. Zhongguo Yi Xue Ke Xue Yuan Xue Bao 36: 218-222, 2014 (In Chinese).

52. Janda E, Lehmann K, Killisch I, Jechlinger M, Herzig M, Downward J, Beug H and Grünert S: Ras and TGF[beta] cooperatively regulate epithelial cell plasticity and metastasis: Dissection of Ras signaling pathways. J Cell Biol 156: 299-313, 2002.

53. Vasko V, Espinosa AV, Scouten W, He H, Auer H, Liyanarachchi S Larin A, Savchenko V, Francis GL, de la Chapelle A, et al: Gene expression and functional evidence of epithelial-to-mesenchyma transition in papillary thyroid carcinoma invasion. Proc Nat Acad Sci USA 104: 2803-2808, 2007

54. Nakajima S, Doi R, Toyoda E, Tsuji S, Wada M, Koizumi M, Tulachan SS, Ito D, Kami K, Mori T, et al: N-cadherin expression and epithelial-mesenchymal transition in pancreatic carcinoma. Clin Cancer Res 10: 4125-4133, 2004
55. Wada N, Duh QY, Sugino K, Iwasaki H, Kameyama K, Mimura T, Ito K, Takami H and Takanashi Y: Lymph node metastasis from 259 papillary thyroid microcarcinomas: Frequency, pattern of occurrence and recurrence, and optimal strategy for neck dissection. Ann Surg 237: 399-407, 2003.

56. Sakorafas GH, Giotakis J and Stafyla V: Papillary thyroid microcarcinoma: A surgical perspective. Cancer Treat Rev 31: 423-438, 2005.

57. White ML, Gauger PG and Doherty GM: Central lymph node dissection in differentiated thyroid cancer. World J Surg 31: 895-904, 2007.

58. Ito Y, Jikuzono T, Higashiyama T, Asahi S, Tomoda C, Takamura Y, Miya A, Kobayashi K, Matsuzuka F, Kuma K and Miyauchi A: Clinical significance of lymph node metastasis of thyroid papillary carcinoma located in one lobe. World J Surg 30: 1821-1828, 2006.

59. Lee YS, Kim SW, Kim SW, Kim SK, Kang HS, Lee ES and Chung KW: Extent of routine central lymph node dissection with small papillary thyroid carcinoma. World J Surg 31: 1954-1959, 2007.

60. Wang W, Gu J, Shang J and Wang K: Correlation analysis on central lymph node metastasis in 276 patients with cN0 papillary thyroid carcinoma. Int J Clin Exp Pathol 6: 510-515, 2013.

61. Shin HJ, Kim EK, Moon HJ, Yoon JH, Han KH and Kwak JY: Can increased tumoral vascularity be a quantitative predicting factor of lymph node metastasis in papillary thyroid microcarcinoma? Endocrine 47: 273-282, 2014.

62. Park YJ, Kim YA, Lee YJ, Kim SH, Park SY, Kim KW, Chung JK, Youn YK, Kim KH, Park DJ and Cho BY: Papillary microcarcinoma in comparison with larger papillary thyroid carcinoma in BRAF(V600E) mutation, clinicopathological features, and immunohistochemical findings. Head Neck 32: 38-45, 2010. 